\title{
Prevalence of Anxiety, Depression and Stress Symptoms and its Association with Neck/Shoulder Pain in Adolescents Athletes
}

\author{
Hítalo Andrade Silva ${ }^{1 *}$, Muana Pereira Passos ${ }^{1}$, Valéria Alves Oliveira ${ }^{1}$, Yslainy Araújo Silva ${ }^{1}$, \\ Ana Carolina Rodarti Pitangui ${ }^{1}$, Rodrigo Cappato Araújo ${ }^{1}$
}

ARTIGO ORIGINAL | ORIGINAL ARTICLE

\begin{abstract}
Psychological distress is among the main causes of the onset or worsening of pain symptoms in young sports people. The increasing participation of adolescents in various sports increases the need to verify the prevalence and association of these affective disorders such as anxiety, stress and depression with pain in the shoulder girdle and in the cervical region that are typical in sportspeople who use more frequently the upper limbs. The sample ( $n=310 ; 14.16 \pm 2.12$ years). Corlett's body diagram and the Brazilian short version of the anxiety, depression and stress scale (DASS-21) were used. Independent t-tests, chi-square and multiple logistic regression were used. The girls had a higher prevalence of anxiety/stress $(62 \%, \mathrm{p}=$ $0.02)$. The variables associated with anxiety/stress were female $(\mathrm{OR}=2.16)$, aged 15 to 19 years $(\mathrm{OR}=$ 2.39) and individual modality $(\mathrm{OR}=1.88)$. The variables associated with depression were age 15 to 19 years $(\mathrm{OR}=1.74)$, individual modality $(\mathrm{OR}=1.84)$ and pain in the shoulder girdle and cervical region $(\mathrm{OR}=2.33)$.

Keywords: Affective Symptoms; Shoulder Pain; Psychology, Sports; Adolescent Behavior
\end{abstract}

\section{INTRODUCTION}

Adolescence is a crucial stage of human development and high prevalence of psychological disorders at this stage of life is a matter of alertness (de Araújo Veras, Ximenes, de Vasconcelos, \& Sougey, 2016). The depression in individuals establishes the presence of negative mood, somatic conditions and cognitive vulnerability, which characterizes it as a complex phenomenon and that especially interferes in their social relations (Nkansah-amankra \& Tettey, 2015). The anxiety and stress can act in several ways in response to different stressors or specific situations perceived as threatening or dangerous. All these forms lead to emotional reactions such as sympathetic nervous activation, worry, nervousness and concern (Basile, Carrasco \& Martorell, 2015).

The individuals with these psychological disorders also presented higher interference of pain in daily life activities and sports (Bair, Wu, Damush, Sutherland, \& Kroenke, 2008) compromising the functional status (George et al., 2011). The sharp increase in the participation of adolescents in sports (Franklin \& Weiss, 2012; Maffulli, Orth, Longo, Spiezia, \& Denaro, 2010), emphasizes the importance of investigating the presence of these disorders in this population. The psychological suffering together with the anatomical characteristics, genetic, structural factors and the lack of conditioning are among the main causes of the onset or worsening of symptoms pain in young athletes (Vikat et al., 2000).

The studies that propose to respond to the existence or not of the association of symptoms of depression, anxiety and stress with pain in adolescents are limited and those that deal with athlete population in this age group are also scarce. Therefore, the present study proposes to verify the prevalence of symptoms of anxiety, depression and stress and their association with pain in the shoulder girdle and cervical region in adolescents, however with a focus on young athletes who use the upper limb with more intensity in their sports. Allowing thus, greater

\footnotetext{
Manuscript received at July $15^{\text {th }} 2016$; Accepted at February $3^{\text {rd }} 2017$

${ }^{1}$ Universidade de Pernambuco, Petrolina-PE, Brazil

* Corresponding author: Rodovia BR 203, km 2, s/n - Vila Eduardo - CEP: 56328-903 - Petrolina, PE, Brazil

E-mail: hitalo_andrade@yahoo.com.br
} 
understanding and clarification about this theme, with the intention of subsidizing multi professional interventions covering the physical and emotional aspects.

\section{METHOD}

\section{Participants}

This is a cross sectional observational descriptive and correlational study. The study population was composed of adolescents' amateur athletes, male and female, aged between 10 and 19 years who practiced at least one of five sports modalities that involved with more emphasis the upper limbs (volleyball, handball, basketball, swimming and judo), in Petrolina city - Pernambuco, in 2015. After a survey conducted in schools and sports centres it was reached a population of 521 adolescents amateur athletes who practiced those modalities. In the study 317 adolescents were assessed, but seven of them were excluded for incomplete questionnaires, resulting in a total of 310 adolescents analysed.

The sample size was quantified through the program WinPepi, using the following criteria: estimated population of 521 amateur athletes; confidence interval of $95 \%$; sample error of five percentage points; estimated prevalence of psychological symptoms in $50 \%$, sample loss of $10 \%$ and sample delineation effect established in 1.2 times the size of the sample, reaching the minimum sample of 296 adolescents.

The exclusion criteria befell on the incomplete completion of the questionnaires and in the refusal to undertake some of the anthropometric measurements. The selection of adolescents in each modality was performed by simple randomization. The present study was approved by the Research Ethics Committee at the University of Pernambuco (UPE), under the protocol number: CCAE 38321114.0.0.0000.5207.

\section{Instruments}

A structured questionnaire was designed containing information on personal data and Sports of the participants (age, sex, sports modality, total time of sports practice, training frequency in days per week and session duration of training in hours per day).
The pain location was performed through the diagram of the body of Corlett, which consists of a map index divided into segments where the participant points specific locations with painful symptoms and can distinguish the presence of pain/discomfort between right and left hemibody. The participants that have signalled to feel pain in at least one of the following locations: neck, cervical region, right shoulder, left shoulder or upper coasts were categorized with presence of pain in the shoulder girdle and cervical region.

The data related to symptoms of anxiety, depression and stress were obtained using the Brazilian version of the scale of anxiety, depression and stress reduced with 21 questions (EADS-21). This version was translated and validated to Portuguese language (Vignola \& Tucci, 2014) and it is a measure of self-report that contains three sub-scales, each one composed of seven items that assess the emotional states of depression, anxiety and stress in the last week. Each item receives a score that ranges from zero to three points, being zero when "disagrees completely" and three when "agrees completely". To calculate the final result of each construct of EADS-21 it is necessary to perform the sum of the scores of the seven items that correspond to construct and multiply by two. The results vary from normal to extremely serious. In the present study the results were reorganized in a dichotomous variable: presence or absence of symptoms. The anxiety and stress subscales different from the original version (Lovibond \& Lovibond, 1995) were analysed based on a joint exploratory factor analysis of the items of the scale, where it was observed that in the adolescent population these two constructs presented issues with strong factorials loads for both, making it difficult to differentiate between them, allowing to infer better data analysis with only two constructs: depression and anxiety/stress (Silva et al., 2016). For measurement of body mass, a mechanical scale duly calibrated was used (Welmi, São Paulo, Brazil). Height was measured using a portable scientific stadiometer (Welmi, São Paulo, Brazil), considering the distance between the stadiometer platform and the header vertex. The subjects performed the inspiration, followed by a 
respiratory blockade for the realization of the measurement. It was calculated the body mass index (BMI) and for the classification of eutrophic and overweight it was used the criteria suggested by the International Obesity Task Force IOTF (Cole, 2000).

\section{Procedures}

The instruments were applied by the previously trained evaluators to avoid possible doubts of the adolescents without interfering in their answers. The questionnaires were delivered after collection of the Informed Consent Form (TCLE) signed by parents or legal guardians and the Term of Assent duly signed and dated by adolescents under 18 years of age. The adolescents responded the instruments individually, with paper and pencil, without the presence of other adolescent, teachers or coaches.

\section{Data analysis}

The data were tabulated in the program Microsoft Excel and the data analysis was performed through the Statistical Package for the Social Sciences (SPSS) version 20.

In the descriptive analysis of categorical variables, it was performed the distribution of frequencies (absolute and relative) and of numerical variables were presented by the values of central tendency and dispersion in accordance with the distribution of the data that was verified through the Kolmogorov-Smirnov test.

It was also conducted the independent $t$ test to establish the averages of the personal characteristics of the adolescents stratified by sex differ significantly. For the study of the association between the two variables it was performed the chi-square statistic test. It was evaluated the variables that entered in the model, the possible confounding factors and if there is need for statistical adjustment of the analyses. It was performed multiple logistic regression through the chances ratio estimate (odds ratio $=$ OR), through the input method step by step backwards (backward stepwise) and confidence intervals of $95 \%$, to express the degree of association between the variables. In this model, after obtaining the predictive variables, it was verified the occurrence of interaction. For entry in the final multiple model, multiple variables were selected whose significance of $\mathrm{p}$ was less than 0.20 in the bivariate regression. In addition, it was applied the tests of Omnibus and HosmerLemeshow to describe the validity and the explanatory power of the final model. In all tests applied it was considered a significance level of $5 \%$.

\section{RESULTS}

The personal characteristics of these adolescents are described in Table 1 with their respective averages and standard deviation of the total sample and stratified by sex. It is possible to observe that the boys showed higher mean age, body mass and stature when compared to girls. In the study 317 adolescents were assessed, but seven of them were excluded for incomplete questionnaires, resulting in a total of 310 adolescents analysed, 131 girls and 179 boys, between 10 and 19 years.

Table 1

Personal characteristics of the total sample and stratified by sex, represented as mean and standard deviation $(n=310)$.

\begin{tabular}{lccccc} 
& \multicolumn{2}{c}{ Personal Characteristics } & & \\
\cline { 2 - 3 } & Total & Male & & Female & $P$ \\
\hline Age & $14.16(2.12)$ & $14.59(2.15)$ & & $13.58(1.95)$ & $<0.001^{*}$ \\
Body Mass $(\mathrm{kg})$ & $58.92(14.88)$ & $63.35(15.55)$ & & $52.79(11.37)$ & $<0.001^{*}$ \\
Height $(\mathrm{m})$ & $1.65(0.12)$ & $1.70(0.12)$ & & $1.59(0.08)$ & $<0.001^{*}$ \\
Body Mass Index $\left(\mathrm{kg} / \mathrm{m}^{2}\right)$ & $21.29(3.77)$ & $21.62(3.93)$ & & $20.82(3.49)$ & 0.06 \\
\hline
\end{tabular}

*Statistically significant

As for sport characteristics of adolescents, the five modalities used in the study were categorized into individual or collective and together with the characteristics related to sports practice and training time are described in Table 2, also in its totality and stratified by sex. None of the sport characteristics presented statistically significant difference between the sexes. 
16 | HA Silva, MP Passos, VA Oliveira, YA Silva, ACR Pitangui, RC Araújo

Table 2

Sports Characteristics of the total sample and stratified by sex, represented in absolute frequency (relative -\%) $(n=310)$.

\begin{tabular}{|c|c|c|c|c|}
\hline Sports Characteristics & Total & Male & Female & $P$ \\
\hline \multicolumn{5}{|l|}{ Sport } \\
\hline Individual & $76(24.5)$ & $50(27.8)$ & $26(20)$ & 0.10 \\
\hline Team & $234(75.5)$ & $130(72.2)$ & $104(80)$ & \\
\hline \multicolumn{5}{|l|}{ Practice Time } \\
\hline 1 year ago & $69(22.3)$ & $42(23.3)$ & $27(20,8)$ & 0.66 \\
\hline Over 1 year & $241(77.7)$ & $138(76.7)$ & $103(79.2)$ & \\
\hline \multicolumn{5}{|l|}{ Frequency of training } \\
\hline Up to 3 times/week & $234(75.5)$ & $136(75.6)$ & $98(75.4)$ & 0.97 \\
\hline More than 3 times/week & $76(24.5)$ & $44(24.4)$ & $32(24.6)$ & \\
\hline \multicolumn{5}{|l|}{ Duration of the training session } \\
\hline Up to 1 hour/day & $49(15.8)$ & $30(16.7)$ & $19(14.6)$ & 0.59 \\
\hline Over 1 hour/day & $261(84.2)$ & $150(83.3)$ & $111(85.4)$ & \\
\hline
\end{tabular}

*Statistically significant

The prevalence of symptoms of anxiety/stress was accounted with the reach of the minimum score to indicate the presence of some symptoms in at least one of the two constructs. The values are shown in table 3 along with the prevalence of depression and the presence of pain in the scapular waist and cervical region, represented in the absolute and relative frequencies in its totality and stratified by sex, in addition to the comparison of averages. Female sex showed higher prevalence of anxiety/stress in relation to the male, now for depression and pain in the scapular waist and cervical region, no significant difference was observed.

Table 3

Prevalence of pain and symptoms of depression and anxiety/stress of the total sample and stratified by sex, represented in absolute and relative frequency $(n=310)$.

\begin{tabular}{lcccc}
\hline Prevalence of Symptoms and Pain & Total & Male & Female & $P$ \\
\hline Anxiety/Stress & & & & \\
$\quad$ With symptoms & $124(40)$ & $62(34.6)$ & $62(47.3)$ & $0.02^{*}$ \\
$\quad 186(60)$ & $117(65.4)$ & $69(52.7)$ & $36(27.5)$ & 0.90 \\
\hline No symptoms & $84(27.1)$ & $48(26.8)$ & $95(72.5)$ & \\
$\quad$ With symptoms & $226(72.9)$ & $131(73.2)$ & $89(67.9)$ & 0.17 \\
$\quad$ No symptoms & $197(63.5)$ & $108(60.3)$ & $42(32.1)$ & \\
\hline Neck/Shoulder & $113(36.5)$ & $71(39.7)$ & & \\
$\quad$ With pain & & & & \\
$\quad$ No pain & & & & \\
\hline
\end{tabular}

*Statistically significant

The model of multiple logistic regression of personal variables and sports of the adolescents, besides the presence and absence of pain in the cervical region and shoulder girdle with the presence or not of the symptoms of anxiety/stress are described in table 4 . The variables that remained in the final model depicting a significant association with the presence of symptoms of anxiety/stress were females ( $\mathrm{p}=$ $0.003)$, the adolescents with 15 to 19 years $(\mathrm{p}=$ $0.001)$ and the individual modality $(\mathrm{p}=0.036)$. The validity of the model was confirmed by the Omnibus test with $\mathrm{p}<0.001$ and presented a high explanatory power with the value of 0.98 in adhesion test Hosmer Lemeshow, demonstrating how well the model fits. 
Table 4

Association of the independent variables with the presence of symptoms of anxiety/stress in adolescents' amateur athletes. $(N=$ 310)

\begin{tabular}{|c|c|c|c|c|c|}
\hline \multirow{2}{*}{$\begin{array}{l}\text { Independent Variables } \\
\text { Sex }\end{array}$} & \multirow[t]{2}{*}{$\begin{array}{c}\text { With Symptoms } \\
\mathrm{n}(\%)\end{array}$} & \multirow[t]{2}{*}{$\begin{array}{c}\text { No Symptoms } \\
\mathrm{n}(\%) \\
\end{array}$} & \multicolumn{2}{|c|}{ OR [IC 95\%] } & \multirow{4}{*}{$\begin{array}{c}\begin{array}{c}\text { Adjusted OR } \\
{[\text { IC95\%] }}\end{array} \\
2.16[1.31-3.57]\end{array}$} \\
\hline & & & & & \\
\hline Female & $62(47.3)$ & $69(52.7)$ & 1.70 & {$[1.07-2.69]$} & \\
\hline Male & $62(34.6)$ & $117(65.4)$ & 1 & & \\
\hline \multicolumn{6}{|l|}{ Age } \\
\hline 10 to 14 years & $55(33.7)$ & $108(66.3)$ & 1 & {$[1.10-2.75]$} & $2.39[1.42-4.01]$ \\
\hline 15 to 19 years & $69(46.9)$ & $78(53.1)$ & 1.74 & & \\
\hline \multicolumn{6}{|l|}{ Body Mass Index } \\
\hline Overweight & $36(43.4)$ & $47(56.6)$ & 1 & {$[0.50-1.38]$} & \\
\hline Normal & $88(38.8)$ & $139(61.2)$ & 0.83 & & \\
\hline \multicolumn{6}{|l|}{ Sport } \\
\hline Individual & $39(51.3)$ & $37(48.7)$ & 1.85 & {$[1.09-3.12]$} & $1.88[1.04-3.39]$ \\
\hline Team & $85(36.3)$ & $149(63.7)$ & 1 & & \\
\hline \multicolumn{6}{|l|}{ Practice Time } \\
\hline 1 year ago & $23(32.9)$ & $47(67.1)$ & 0,67 & {$[0.38-1.18]$} & \\
\hline Over 1 year & $101(42.1)$ & $139(57.9)$ & 1 & & \\
\hline \multicolumn{6}{|l|}{ Frequency of training } \\
\hline Up to 3 times/week & $92(39.3)$ & $142(60.7)$ & 0.90 & {$[0.53-1.51]$} & \\
\hline More than 3 times/week & $32(42.1)$ & $44(57.9)$ & 1 & & \\
\hline \multicolumn{6}{|c|}{ Duration of the training session } \\
\hline Up to 1 hour/day & $25(51)$ & $24(49)$ & 1.70 & {$[0.92-3.15]$} & \\
\hline Over 1 hour/day & 99 (37.9) & $162(62.1)$ & 1 & & \\
\hline \multicolumn{6}{|l|}{ Neck/Shoulder } \\
\hline With pain & $88(44.7)$ & $109(55.3)$ & 1.73 & {$[1.06-2.80]$} & \\
\hline No pain & $36(31.9)$ & $77(68.1)$ & 1 & & \\
\hline
\end{tabular}

Table 5

Association of the independent variables with the presence of symptoms of depression in teens amateur athletes. $(N=310)$

\begin{tabular}{|c|c|c|c|c|c|}
\hline \multirow{2}{*}{$\begin{array}{l}\text { Independent Variables } \\
\text { Sex }\end{array}$} & \multirow[t]{2}{*}{$\begin{array}{c}\text { With Symptoms } \\
\mathrm{n}(\%)\end{array}$} & \multirow[t]{2}{*}{$\begin{array}{c}\text { No Symptoms } \\
\text { n (\%) }\end{array}$} & \multicolumn{2}{|c|}{ OR [IC 95\%] } & \multirow[t]{2}{*}{$\begin{array}{c}\text { Adjusted OR } \\
\text { [IC95\%] }\end{array}$} \\
\hline & & & & & \\
\hline Female & $36(27.5)$ & $95(72.5)$ & 1.03 & {$[0.62-1.71]$} & \\
\hline Male & $48(26.8)$ & $131(73.2)$ & 1 & & \\
\hline \multicolumn{6}{|l|}{ Age } \\
\hline 10 to 14 years & $36(22.1)$ & $127(77.9)$ & 1 & {$[1.03-2.84]$} & $1.74[1.03-2.95]$ \\
\hline 15 to 19 years & $48(32.7)$ & $99(67.3)$ & 1.71 & & \\
\hline \multicolumn{6}{|l|}{ Body Mass Index } \\
\hline Overweight & $22(26.5)$ & $61(73.5)$ & 0.96 & {$[0.54-1.70]$} & \\
\hline Normal & $62(27.3)$ & $165(72.7)$ & 1 & & \\
\hline \multicolumn{6}{|l|}{ Sport } \\
\hline Individual & $27(35.5)$ & $49(64.5)$ & 1.71 & {$[0.98-2.98]$} & $1.84[1.03-3.28]$ \\
\hline Team & $57(24.4)$ & $177(75.6)$ & 1 & & \\
\hline \multicolumn{6}{|l|}{ Practice Time } \\
\hline 1 year ago & $15(21.4)$ & $55(78.6)$ & 0.68 & {$[0.36-1.28]$} & \\
\hline Over 1 year & $69(28.8)$ & $171(71.2)$ & 1 & & \\
\hline \multicolumn{6}{|l|}{ Frequency of training } \\
\hline Up to 3 times/week & $68(29.1)$ & $166(70.9)$ & 1 & {$[0.35-1.21]$} & \\
\hline More than 3 times/week & $16(21.1)$ & $60(78.9)$ & 0.65 & & \\
\hline \multicolumn{6}{|c|}{ Duration of the training session } \\
\hline Up to 1 hour/day & $17(34.7)$ & $32(65.3)$ & 1 & {$[0.34-1.25]$} & \\
\hline Over 1 hour/day & $67(25.7)$ & $194(74.3)$ & 0.65 & & \\
\hline \multicolumn{6}{|l|}{ Neck/Shoulder } \\
\hline With pain & $65(33.0)$ & $132(67.0)$ & 2.44 & {$[1.37-4.33]$} & $2.33[1.30-4.19]$ \\
\hline No pain & $19(16.8)$ & $94(83.2)$ & 1 & & \\
\hline
\end{tabular}


In the second model of multiple logistic regression it was considered as a dependent variable the presence or absence of symptoms of depression and it is exposed in table 5. The variables that remained in the final model with significant association were the age range from 15 to 19 years $(\mathrm{p}=0.037)$, the individual modality $(\mathrm{p}=0.040)$ and the presence of pain in the scapular waist and cervical region $(p=0.005)$. The model also showed to be valid with the Omnibus test de $p<0.001$ and a high explanatory power (Hosmer-Lemeshow test of 0.99).

\section{DISCUSSION}

In the present study, psychological disorders showed high rates of prevalence. Almost half of the girls $(47.3 \%)$ and one third of the boys presented symptoms of anxiety/stress, and a forth not only concerning the girls but also to the boys expressed symptoms of depression. As to the painful symptoms in the cervical region and shoulder girdle, over $60 \%$ of the adolescents were affected. The adolescents between 15 and 19 years and those who practice individual modalities presented association with the presence of symptoms of anxiety/stress and depression. The girls obtained more chances of presenting symptoms of anxiety/stress and adolescents with pain in the cervical region and in the scapular waist had more chances of presenting symptoms of depression.

The prevalence of psychological disorders in adolescents agrees with epidemiological surveys that show a pattern of increasing prevalence of these symptoms, especially among girls (Kessler, Avenevoli, \& Ries Merikangas, 2001). The use of scales and questionnaires for the collection of such data may be the explanation of this high prevalence, due to over registrations of light and momentary mood disorders, that in a more specific evaluation would not be considered. Even so, the self-reports are important for informing the unique insight to the individual on aspects of their own behaviour (Kohlsdorf \& Junior, 2009).

The anxiety/stress was the most frequently reported symptom by adolescents, being that the girls showed higher prevalence when compared to boys. Studies with adolescents which emphasize the differences found between the sexes are crucial for better clarification of the differences found in the rates of mental disorders among sexes in adulthood. It is possible to say that many of the disorders found in adults were developed in very young ages (Warner \& Bott, 2010). In the present study it was observed that the girls had more chances of presenting symptoms of anxiety, which corroborates the higher rates of anxiety in women in adult age (Kinrys \& Wygant, 2005).

The anxiety is not only the most common disorder among the American adolescents (Merikangas et al., 2010), but also the girls are the most affected ones (Jin et al., 2014; Merikangas et al., 2010; Yao et al., 2015). The differences of anxiety between the sexes go beyond the prevalence, there are also differences in the clinical presentation and in their characteristics. The females tend to report greater severity of symptoms and show comorbidities with more frequency when compared to male patients who tend to have greater resistance to expressing their psychological symptoms. It is also suggested that the genetic factors and sex hormones may also play important roles in the expression of these differences between the sexes (Kinrys \& Wygant, 2005).

Another factor that proved to be associated with psychological disorders was the age, both for the anxiety/stress and for depression. It was evidenced a greater chance of the older adolescents, between 15 and 19 years, presenting symptoms of anxiety/stress and depression. The adolescence being a transition phase and of constant physical and psychological changes, propitiates the adolescents more chances of presenting these symptoms, therefore, the way the adolescence is experienced can influence on changes in adulthood (Argimon, Terroso, Barbosa, \& Lopes, 2013).

Our findings corroborate the study of Jin et al. (2014) who also found a directly proportional relationship, increasing the prevalence of anxiety according to the increase of the school level, which would indicate that as the school degree rises, consequently the age, the stress of these adolescents intensifies in two main aspects, both in pressure of learning, as in the increase of interpersonal relations. Now for depression a 
meta-analysis study (Twenge \& NolenHoeksema, 2002) sought to evaluate the influences of several sociodemographic factors in their prevalence, among them the age. It was observed that the prevalence of depression in girls remained stable until the age of 12 years old and then increased as they aged. The explanation would be also in the influence of sex, the girls, more briefly than the boys, between 12 and 16 years are in puberty and due to hormonal action feature more depression symptoms.

The physical activity is considered a protective factor, thus decreasing the chances of individuals presenting symptoms of psychological disorders, mainly of depression in women (Dugan, Bromberger, Segawa, Avery, \& Sternfeld, 2015). The practice of sports during adolescence was associated with lower scores of depression symptoms in adulthood. The explanation for this was that the physical activity in a context of organized sport favours the positive mental health, in addition to providing opportunities for social interaction and connectivity (Brunet et al., 2013). In the study of the Jewett et al. (2014) it was observed that the involvement of adolescents in sports at school was associated with the decrease of both symptoms of depression and stress, highlighting the importance of social factors that connect the participation in sports with mental health during adolescence and early adulthood.

In the present study the entire sample practiced sports activities, within this practice, the collective sports were considered a protective factor for the presence of psychological disorders. The adolescents of individual sports obtained more chances of presenting symptoms of anxiety/stress and depression. There are no longitudinal studies demonstrating the connection between the nature of the involvement with symptoms of psychological disorders. It is possible that the participation of sports involving people competing against each other for personal objective (individual) modality is less protective than the participation in sports involving a group of people working together for a shared goal modality (collective) mainly due the social nature (Eime, Young, Harvey, Charity, \& Payne, 2013).
The pain in the cervical region is the fourth most common disorder in the global population (Vos et al., 2012), and together with the shoulder pain presented a high prevalence in the last decades among adolescents with a tendency to continue raising (Hakala, Rimpelä, Salminen, Virtanen, \& Rimpelä, 2002). In this study the adolescents with pain in the cervical region and shoulder girdle presented a high prevalence. Showing to be a common problem and growing at this stage of life (Vikat et al., 2000), and suggesting to be a problem in adults of the future.

Based on the theory of reciprocity between pain and depression, in which nociceptive pain can have its threshold both reduced by psychological suffering as can also be the consequence (Vikat et al., 2000), several studies (Diepenmaat, Wal, Vet, \& Hirasing, 2006; Härmä, Kaltiala-Heino, Rimpelä, \& Rantanen, 2002; Myrtveit et al., 2014; Ståhl et al., 2008) are in accordance with the present research, indicating that adolescents with pain in the cervical region and in the shoulder girdle had more chances of presenting depressive symptoms. The negative affectivity in response to noxious stimulation, leads to fear, to avoid specific movements, the disuse and incapacity. In turn, this can increase the pain experience, because it is about a bidirectional association (Cotchett, Munteanu, \& Landorf, 2016).

The study of Richards, Beales, Smith, O'Sullivan, and Straker (2016) did not evaluate the association of pain in the cervical region with depression, but they observed that four types of postures are the most common among the adolescents, the hyperkyphosis posture and protruded head was the one which had more chances of presenting depressive symptoms. Suggesting that adolescents with this type of attitude, as time goes by, can acquire dysfunctions in this region which consequently provoke pain symptoms. Pain can both be changed by affective diseases, as induce or exacerbate an affective dysphoric state (Korff \& Simon, 1996). Psychosocial factors amplify the experience of pain and thus perpetuate a vicious circle of nociception, pain, anguish and incapacity (Gatchel, Peng, Peters, Fuchs, \& Turk, 2007). As the depression and the pain share a common 
chemical pathway and both are influenced by the levels of serotonin and norepinephrine, both of them should be treated together (Trivedi, 2004). Indicating that the improvement of the physical symptom would improve the symptoms of depression and suggesting that the reverse is also possible.

\section{CONCLUSION}

The present study concludes that psychological disorders and painful symptoms showed high levels of prevalence in adolescents, especially in girls. Older adolescents and practicing individual sports showed more odds to have symptoms of anxiety/stress and depression. The girls obtained more odds to have symptoms of anxiety/stress and adolescents with neck/shoulder pain had more odds to have symptoms of depression.

It is important to note that the study focused on the use of an instrument of self-report and it cannot infer categorically that the adolescents presented those disorders based only on scale scores. The study also makes evident the clear and mutual interaction between the psychological symptoms and pain. It becomes indispensable longitudinal studies that seek to demonstrate the effectiveness of interventions that integrate physical and psychosocial therapies for pain relief, mainly for the adolescents who are overtaking a sensitive stage of sudden and frequent changes, with direct reactions in adulthood.

Acknowledgments:

Nothing to declare.

\section{Conflict of interests:}

Nothing to declare.

\section{Funding:}

Nothing to declare.

\section{REFERENCES}

Argimon, I. I. de L., Terroso, L. B., Barbosa, A. de S., \& Lopes, R. M. F. (2013). Intensidade de sintomas depressivos em adolescentes através da escala de depressão de Beck (BDI-II). Boletim - Academia.
Paulista de Psicologia, 33(85), 354-372.

Basile, S.. Carrasco, M. A., Martorell, J. L. (2015). Preocupaciones excesivas en la adolescencia: descripción, evaluación y tratamiento de un caso de ansiedad generalizada Clínica y Salud, 26(3), 121-129. https://dx.doi.org/0.1016/j.clysa.2015.09.001

Bair, M. J., Wu, J., Damush, T. M., Sutherland, J. M., \& Kroenke, K. (2008). Association of Depression and Anxiety Alone and in Combination With Chronic Musculoskeletal Pain in Primary Care Patients. Psychosomatic Medicine, 70(8), 890-897. https://doi.org/10.1097/PSY.0b013e318185c51 0

Brunet, J., Sabiston, C. M., Chaiton, M., Barnett, T. A., O'Loughlin, E., Low, N. C. P., \& O'Loughlin, J. L. (2013). The association between past and current physical activity and depressive symptoms in young adults: A 10-year prospective study. Annals of Epidemiology, 23(1), 25-30. https://doi:10.1016/j.annepidem.2012.10.006

Cole, T. J. (2000). Establishing a standard definition for child overweight and obesity worldwide: international survey. BMJ, 320(7244), 12401240. https://doi:10.1136/bmj.320.7244.1240

Cotchett, M., Munteanu, S. E., \& Landorf, K. B. (2016). Depression, Anxiety, and Stress in People With and Without Plantar Heel Pain. Foot \& Ankle International, $\quad 37(8), \quad 816-821$. https://doi.org/10.1177/1071100716646630

de Araújo Veras, J. L., Ximenes, R. C. C., de Vasconcelos, F. M. N., \& Sougey, E. B. (2016). Prevalence of Suicide Risk Among Adolescents With Depressive Symptoms. Archives of Psychiatric Nursing, 30(1), 2-6. https://doi.org/10.1016/j.apnu.2015.11.003

Diepenmaat, A. C. M., Wal, M. F. Van Der, Vet, H. C. W. de, \& Hirasing, R. A. (2006). Neck/shoulder, low back, and arm pain in relation to computer use, physical activity, stress, and depression among Dutch adolescents. Pediatrics, 117(2), 412-6. https://doi.org/10.1542/peds.2004-2766

Dugan, S. A., Bromberger, J. T., Segawa, E., Avery, E., \& Sternfeld, B. (2015). Association between Physical Activity and Depressive Symptoms. Medicine \& Science in Sports \& Exercise, 47(2), 335342.

https://doi.org/10.1249/MSS.00000000000004 07

Eime, R. M., Young, J. a, Harvey, J. T., Charity, M. J., \& Payne, W. R. (2013). A systematic review of the psychological and social benefits of participation in sport for children and adolescents: Informing development of a conceptual model of health through sport. International Journal of Behavioral Nutrition and Physical Activity, 10, 98-119. https://doi.org/10.1186/1479-5868-10-98

Franklin, C. C., \& Weiss, J. M. (2012). Stopping sports injuries in kids: an overview of the last year in publications. Current Opinion in Pediatrics, 24(1), 64-7.

https://doi.org/10.1097/MOP.0b013e32834ec6 
18

Gatchel, R. J., Peng, Y. B., Peters, M. L., Fuchs, P. N., \& Turk, D. C. (2007). The biopsychosocial approach to chronic pain: Scientific advances and future directions. Psychological Bulletin, 133(4), 581-624. https://doi.org/10.1037/00332909.133.4.581

George, S. Z., Coronado, R. a, Beneciuk, J. M., Valencia, C., Werneke, M. W., \& Hart, D. L. (2011). Depressive symptoms, anatomical region, and clinical outcomes for patients seeking outpatient physical therapy for musculoskeletal pain. Physical Therapy, 91(3), 358-72. https://doi.org/10.2522/ptj.20100192

Hakala, P., Rimpelä, A., Salminen, J. J., Virtanen, S. M., \& Rimpelä, M. (2002). Back, neck, and shoulder pain in Finnish adolescents: national cross sectional surveys. BMJ (Clinical Research Ed.), 325(7367), 743. https://doi.org/10.1136/bmj.325.7367.743

Härmä, A.-M., Kaltiala-Heino, R., Rimpelä, M., \& Rantanen, P. (2002). Are adolescents with frequent pain symptoms more depressed? Scandinavian Journal of Primary Health Care, 20(2), 92-96.

Jewett, R., Sabiston, C. M., Brunet, J., O’Loughlin, E. K., Scarapicchia, T., \& O'Loughlin, J. (2014). School sport participation during adolescence and mental health in early adulthood. Journal of Adolescent Health, 55(5), 640-644. https://doi.org/10.1016/j.jadohealth.2014.04.0 18

Jin, Y., He, L., Kang, Y., Chen, Y., Lu, W., Ren, X., ... Yao, Y. (2014). Prevalence and risk factors of anxiety status among students aged 13-26 years. International Journal of Clinical and Experimental Medicine, 7(11), 4420-4426.

Kessler, R. C., Avenevoli, S., \& Ries Merikangas, K. (2001). Mood disorders in children and adolescents: an epidemiologic perspective. Biological Psychiatry, 49(12), 1002-1014. https://doi.org/10.1016/S00063223(01)01129-5

Kinrys, G., \& Wygant, L. E. (2005). Transtornos de ansiedade em mulheres: gênero influencia o tratamento? Revista Brasileira de Psiquiatria, 27(617), 43-50. https://doi.org/10.1590/S151644462005000600003

Kohlsdorf, M., \& Junior, Á. L. da C. (2009). O Autorrelato na Pesquisa em Psicologia da Súde: Desafios metodológicos. Psicologia. Argumento., 27(57), 131-139.

Korff, M. Von, \& Simon, G. (1996). The Relationship Between Pain and Depression. The British Journal of Psychiatry, 168(30), 101-108.

Lovibond, P. F., \& Lovibond, S. H. (1995). The structure of negative emotional states: Comparison of the depression anxiety stress scales (DASS) with the Beck Depression and Anxiety Inventories. Behaviour Research and Therapy, 33(3), 335-343. https://doi.org/10.1016/0005-7967(94)00075$\mathrm{U}$

Maffulli, N., Orth, F., Longo, U. G., Spiezia, F., \& Denaro, V. (2010). Sports Injuries in Young Athletes: Long-Term Outcome and Prevention Strategies. The Physician and Sportsmedicine, 38(2), 29-34.

Merikangas, K. R., He, J.-P., Burstein, M., Swanson, S. a, Avenevoli, S., Cui, L., ... Swendsen, J. (2010). Lifetime Prevalence of Mental Disorders in U.S. Adolescents: Results from the Adolescent Supplement (NCS-A). Journal of the American Academy of Child and Adolescent Psychiatry, 49(10), 980-9.

https://doi.org/10.1016/j.jaac.2010.05.017

Myrtveit, S. M., Sivertsen, B., Skogen, J. C., Frostholm, L., Stormark, K. M., \& Hysing, M. (2014). Adolescent neck and shoulder pain-the association with depression, physical activity, screen-based activities, and use of health care services. The Journal of Adolescent Health: Official Publication of the Society for Adolescent Medicine, 55(3),

366-72. https://doi.org/10.1016/j.jadohealth.2014.02.0 16

Nkansah-amankra, S., \& Tettey, G. (2015). Association between depressive symptoms in adolescence and birth outcomes in early adulthood using a population-based sample. Preventive Medicine Reports, $\quad$ 2, 371-378. https://doi.org/10.1016/j.pmedr.2015.04.016

Richards, K. V., Beales, D. J., Smith, A. J., O'Sullivan, P. B., \& Straker, L. M. (2016). Neck Posture Clusters and Their Association With Biopsychosocial Factors and Neck Pain in Australian Adolescents. Physical Therapy. https://doi.org/10.2522/ptj.20150660

Silva, H. A. da, Passos, M. H. P. dos, Oliveira, V. M. A. de, Palmeira, A. C., Pitangui, A. C. R., \& Araújo, R. C. de. (2016). Short version of the Depression Anxiety Stress Scale-21: is it valid for Brazilian adolescents? Einstein (São Paulo), 14(4), 486-493. https://doi.org/10.1590/s1679$45082016 a 03732$

Ståhl, M., Kautiainen, H., El-Metwally, A., Häkkinen, A., Ylinen, J., Salminen, J. J., \& Mikkelsson, M. (2008). Non-specific neck pain in schoolchildren: Prognosis and risk factors for occurrence and persistence. A 4-year follow-up study. Pain, 137(2), 316-322. https://doi.org/10.1016/j.pain.2007.09.012

Trivedi, M. H. (2004). The link between depression and physical symptoms. Primary Care Companion to the Journal of Clinical Psychiatry, 6(Suppl 1), 126.

Twenge, J. M., \& Nolen-Hoeksema, S. (2002). Age, gender, race, socioeconomic status, and birth cohort difference on the children's depression inventory: A meta-analysis. Journal of Abnormal Psychology, 111(4), 578-588. https://doi.org/10.1037//0021-843X.111.4.578

Vignola, R. C. B., \& Tucci, A. M. (2014). Adaptation 
and validation of the depression, anxiety and stress scale (DASS) to Brazilian Portuguese. Journal of Affective Disorders, 155(1), 104-109. https://doi.org/10.1016/j.jad.2013.10.031

Vikat, A., Rimpela, M., Salminen, J. J., Rimpela, A., Savolainen, A., \& Virtanen, S. M. (2000). Neck or shoulder pain and low back pain in Finnish adolescents. Scandinavian Journal of Public Health, $28,164-173$

Vos, T., Flaxman, A. D., Naghavi, M., Lozano, R., Michaud, C., Ezzati, M., ... Moradi-Lakeh, M. (2012). Years lived with disability (YLDs) for 1160 sequelae of 289 diseases and injuries 19902010: A systematic analysis for the Global Burden of Disease Study 2010. The Lancet, 380(9859),
https://doi.org/10.1016/S01406736(12)61729-2

Warner, L. A., \& Bott, C. (2010). Epidemiology of Mental Disorders in Girls and Female Adolescents. In B. L. Levin \& M. A. Becker (Eds.), A Public Health Perspective of Women's Mental Health (pp. 11-35). Springer, New York, NY. https://doi.org/10.1007/978-1-4419-152692

Yao, Y., Wang, L., Chen, Y., Kang, Y., Gu, Q., Fang, W., ... Guo, D. (2015). Correlation analysis of anxiety status and sub-health status among students of 13-26 years old. International Journal of Clinical and Experimental Medicine, 8(6), 98109814.

All content of Journal Motricidade is licensed under Creative Commons, except when otherwise specified and in content retrieved from other bibliographic sources. 